\title{
A review on motivational nudges for enhancing building energy conservation behavior
}

\author{
Altaf Mazhar Soomro, Gnana Bharathy ${ }^{2}$, Nimish Biloria $^{3}$, Mukesh Prasad ${ }^{1}$ \\ ${ }^{1}$ School of Computer Science, University of Technology Sydney, Sydney 2007, Australia. \\ ${ }^{2}$ School of Information, Systems and Modelling, University of Technology Sydney, Sydney 2007, Australia. \\ ${ }^{3}$ School of Architecture, University of Technology Sydney, Sydney 2007, Australia.
}

Correspondence to: Dr. Mukesh Prasad, School of Computer Science, University of Technology Sydney, Sydney 2007, Australia. E-mail: Mukesh.Prasad@uts.edu.au

\begin{abstract}
How to cite this article: Soomro AM, Bharathy G, Biloria N, Prasad M. A review on motivational nudges for enhancing building energy conservation behavior. J Smart Environ Green Comput 2021;1:3-20. https://dx.doi.org/10.20517/jsegc.2020.03
\end{abstract}

Received: 14 Dec 2020 First Decision: 13 Jan 2021 Revised: 1 Feb 2021 Accepted: 24 Feb 2021 Available online: 30 Mar 2021

Academic Editor: Edmundas Zavadskas Copy Editor: Yue-Yue Zhang Production Editor: Yue-Yue Zhang

\begin{abstract}
This paper explores energy use interventions and their influence on human behavior in commercial and institutional buildings. The main objectives of this paper are to identify the importance of nudges in reducing building energy usage and the implementation methods that can influence users to conserve energy in buildings through context specific interventions. A qualitative research method is used to elicit existing energy saving techniques, and a rigorous literature review is conducted to demonstrate the effectiveness of nudges. The investigation shows that combining multiple influencing options and interactive technological interventions can result in an effective nudging mechanism at a larger scale. Widely adopted technological tools identified in energy conservation in buildings included eco-feedback systems, loT engagement systems, and recommendation systems that shared clear information to enable users to change their behavior. Besides, non-technological tools, such as posters and moral appeal by word of mouth, are highlighted as influencing user behavior to conserve energy in buildings. The use of nudges in commercial and institutional buildings has been studied in this review, and it has been demonstrated that the combination of influencing techniques is more effective than deploying a particular technique. It is concluded that energy conservation can be predicated in agent-based environments by modeling integrated nudges in future work.
\end{abstract}

Keywords: Energy conservation, energy efficiency, energy saving, commercial buildings, institutional buildings, nudging, behavioral influencing strategies 


\section{INTRODUCTION}

Climate change ${ }^{[1]}$, and its subsequent impacts on the lives of inhabitants and infrastructure is a significant problem globally. Addressing this challenge is core to the people, organizations, or governments who realize its catastrophic impacts on inhabitants' survivability. Although many elements are causing climatic shifts, damage from the excessive production of carbon emission is inevitable. Buildings, mainly commercial and institutional buildings, are among the sources that consume a massive amount of energy and become the source of producing carbon emissions. 'International Energy Outlook 2016 With Projections to 2040' report indicates an estimated $41 \%$ of energy is used by buildings ${ }^{[2]}$. A significant proportion of the total energy consumed across the world is attributed to buildings ${ }^{[3-5]}$; for instance, in Hong Kong, buildings account for $90 \%$ of the electricity consumed with, $30 \%$ of this consumed energy attributed to residential buildings. Likewise $^{[3]}$ in India, 35\% of the total energy consumed is attributed to the buildings sector.

A recent study reveals that buildings alone consume 39\% of energy in metropolitan China due to increased urban population, which accounts for up to $8 \%$ of overall China's energy consumption ${ }^{[6]}$. Similarly, findings show excessive energy use in the Indian subcontinent and expose that $37 \%$ of power is supplied into buildings ${ }^{[3]}$. The global construction industry is also expecting to grow annually by $3.6 \%(2018-2022)^{[7]}$. Therefore, it is inevitable to address energy consumption problems, particularly the issue of excessive energy waste.

Thus, the paper proposes ways in which energy conservation in buildings can be achieved by creating the least user discomfort. Energy conservation plays a significant role in environmental sustainability and can economically benefit building owners and managers due to reduced billing $\operatorname{costs}^{[8]}$. This study further demonstrates that the organizations embrace renewable energy supplies to outweigh the excessive energy consumption. There are various energy conservation and optimization techniques, including the traditional ones such as natural ventilation, adopting renewable energy technologies, improving building design and orientation to amplify solar intake, saving excess energy, and innovating conservation strategies tailored to traditional architecture ${ }^{[\rho]}$. Paone and Bacher argue that much research attention has been directed towards developing technical solutions to reduce energy usage, such as smart meters, occupancy sensing, sensor technologies, and mobile applications while neglecting the importance of modifying human behavior ${ }^{[4]}$.

This paper mainly reviews the literature where the implementation of nudges for energy conservation in commercial or institutional buildings has been studied. Nudges in behavioral economics refer to techniques employed by policymakers and choice architects to modify individuals' behavior in an easy and low-cost manner without reducing the number of alternatives available ${ }^{[10]}$. Although the nudge mechanism cannot be generalized in all the contexts associated with behavioral changes due to the complex nature of human behavior, it can enhance the performance of other policy tools with minimum $\operatorname{cost}^{[11]}$. Nudging has a more empirical approach in its design and validation in experiments and controlled trials. Nudging tools complement existing policy tools rather than replacing them ${ }^{[11]}$. Therefore, this research expands the discussion that by investing in technical solutions and fostering parallel changes in human behavior through effective nudges, building energy efficiency can be improved.

The paper is categorically divided into five sections. Section 1 is the introduction that describes a general understanding of building energy consumption and methods for influencing human behavior towards energy conservation through nudges. Section 2 is problem identification, where occupant behavior as a root solution for energy conservation has been discussed and further supported with the underlying theoretical concepts and existing methods. Section 3 is the conceptual model and its validation that expands upon nudges, their implication, and effectiveness in the building energy context. A conceptual model is also 
established to conclude this section. Section 4 is a literature review, demonstrating a qualitative analysis of nudges and their use in different buildings (i.e., office, institutional, educational, and commercial buildings). The final section 5 is the conclusion and future directions.

\section{PROBLEM IDENTIFICATION}

\section{Occupancy behavior and energy conservation}

Occupant behavior describes occupants' presence and interaction with their environments that, subsequently, influence energy consumption ${ }^{[12]}$. Occupant behavior is a critical component in building energy conservation. The development of smart tools and strategies is vital in making buildings energy efficient. Many developed countries are desperately setting certain thresholds to reduce building energy use and have been deploying methods ${ }^{[13]}$ and modern technologies in households ${ }^{[14]}$ and in buildings ${ }^{[15]}$ to reach energy-saving targets. Technical solutions and engineered systems, such as predictive control techniques ${ }^{[16,17]}$ and cost reduction approaches ${ }^{[18]}$, have helped improve existing energy systems to conserve energy using occupancy tracking.

Although traditional techniques establish the roadmap for minimizing energy consumption at the preoccupancy stage of a building, the challenge remains unaddressed if measures are not taken at the postoccupancy stage. A discrepancy exists between a building's predicted energy consumption levels, generated during its design, and actual energy consumed in the developed building ${ }^{[19]}$. Furthermore, such a discrepancy can be vast and can be up to $300 \%$ greater than the predicted energy consumption in some instance $^{[20]}$. Before developing behavior-altering strategies, understanding post-occupancy behavior is thus very crucial. Occupancy sensing helps identify occupants' energy use preferences and enables building control systems to optimize building energy use.

When integrated with the building energy management system, occupancy sensing helps energy control systems optimize energy use within buildings. In the study by Rafsanjani et al. ${ }^{[21]}$, it was argued that capturing the building occupants' consumption data was generally expensive despite the high levels of energy consumption associated with the occupants. As a result, a Non-Intrusive Occupant Load Monitoring strategy was proposed to capture both occupancy-sensing data from existing Wi-Fi systems and changes in power in aggregate buildings. Further to this, findings showed that tracking the occupants' energyconsumption behavior was at a minimal cost and, subsequently, presented an opportunity to save more energy in commercial buildings.

Occupancy sensing has its advantage in understanding occupant energy behavior. When understood with the principle of behavioral economics, occupancy behavior brings opportunities to establish influencing strategies for pro-environmental behavior. Several studies have provided solutions based on occupancy behavior and the underlying theoretical concepts to promote energy conservation in residential buildings. There is a clear gap in exploring integrated models that combine theories and occupancy data to guide the energy conservation practices in commercial and particularly in University or educational buildings.

\section{Underlying theories and influencing techniques}

Despite the technological solutions to improve building energy efficiency, a rigorous approach considering social perspectives (i.e., human behavior and motivation) ${ }^{[22]}$ needs research attention to achieve optimal building energy conservation. The underlying mechanism that forms human behavior has remained researchers' fascination for several years ${ }^{[23]}$. Various theories are explored and tested to understand human behavior in different contexts. Among them, the Theory of Planned Behavior (TPB ${ }^{[24]}$ has been one of the most dominant models. TPB has remained a foundational paradigm in understanding and investigating 
human behavior and its influence from different perspectives. TPB describes that the behavior or action is associated with its intention and that, in turn, is associated with the attitude toward that action or the intention of that action ${ }^{[23]}$. Simplistically, humans act efficiently and comfortably when they have control over their actions.

Furthermore, studies have discovered that applying concepts from the TPB on behavioral intentions of energy regarding policy recommendations and suggestions is useful in energy conservation ${ }^{[25,26]}$. A link between the identity of the environmental issues and behaviors for energy conservation due to the test on account of the expanded TPB model is shown in $\mathrm{Hu}$ et al. ${ }^{[25]}$. Under this expanded model, the proenvironmental identity variable is considered an independent cause that allows building designers to adopt energy conservation practices with high significance levels observed in the link.

The occupants' behavior is usually cited as a significant factor considering its massive influence on building energy performance ${ }^{[27]}$. Conversely, the researchers discovered that it is crucial to consider the link between the occupants' attitudes and behavior during building design and operation. A survey study was conducted by Allen and Marquart-Pyatt ${ }^{[28]}$ to analyze the occupancy activities in three buildings. The study applied the ordinary least regression analysis to investigate the theory of planned behavior and the attitudes behavior constraints model in examining the major energy behavior drivers. The researchers concluded that a higher percentage of the participants would support the application of energy reduction policies and technologically-based interventions and increase the rate of application of renewable resources ${ }^{[28]}$. The outcome of this study provided proof that the ABC model is relevant in the behavioral context. A research study on behavioral models is conducted by Blanke et al. ${ }^{[29]}$, where the models are used to develop energy optimization strategies that account for the physical assets and incorporate building occupants in the process. The researchers concluded that while specific methods, like smart metering and gamification, could address some energy consumption issues, holistic behavioral models could be employed to a broader range of individuals.

Another theory naming Value Belief Norm (VBN), was found by Stern et al. ${ }^{[30]}$ to study peoples' environmental behavior. The VBN identifies an underlying series of relationships between a person's core values and beliefs that form pro-environmental norms that trigger a range of actions taken by the person ${ }^{[31]}$. VBN attempts to explain environmentally significant behaviors and leans more towards environmental behaviors leading to sustainability and thus differs from the TPB. It is worth acknowledging that VBN itself is derived from a composition of three theories, namely Value Theory by Schwartz ${ }^{[32]}$, the New Ecological Paradigm by Dunlap et al. ${ }^{[33]}$, and Norm Activation Theory by Schwartz ${ }^{[34]}$. However, delving into these individual theories is not necessary, as VBN covers and integrates them, and for this particular context supersedes them. Similarly, Attitude-Behavior-Context Theory by Guagnano et al. ${ }^{[35]}$ complements VBN by relating attitude and context to behavior.

Understanding and altering human behavior in the context of energy has also been addressed with the Transtheoretical Model ${ }^{[36]}$. The underlying structure of the Transtheoretical Model is based on a 5 step sequence of behavioral change. A diverse set of interventions are evident in the study by Ernecoff et al. ${ }^{[37]}$, where an agent-based approach is used to alter the user/agent's health behavior.

\section{Methods}

A qualitative research method is adopted to present existing energy conservation methods. A secondary literature review is incorporated as the core methodology, where the evaluation of nudges is demonstrated. A vast literature is available on domestic energy conservation using numerous methods. However, in the 
past few years, development in energy conservation in the building sector has grown. Several methods have been established and deployed to conserve energy within buildings, including traditional methods, technical solutions, and behavioral influencing techniques. This study generally presents some energy conservation methods and particularly emphasizes the behavioral influencing methods highlighting and drawing insights from "The Behavior Change Wheel" ${ }^{[38]}$, as shown in Figure 1. The behavior change wheel is a three-layered non-linear model representing behavioral sources, intervention functions, and policy categories ${ }^{[38]}$. The policy implication is the ultimate objective when influencing energy behavior and is at the core of any energy efficiency program. We illustrate intervention functions from the behavior change wheel and demonstrate their interrelationship with the energy conservation methods in Figure 1.

Some inferences are made in Figure 1, demonstrating the association between energy conservation methods and the intervention functions. These include the categories that match the traditional methods and technological methods, such as environmental restructuring. Environmental restructuring can directly link to building orientation, design, and building control systems. However, the other technological methods, for example, user engagement and gamified platforms, deploy modeling and user enabling interventions for energy conservation. Finally, the core interventions that directly impact the behavior and fall under the socio-psychological paradigm are education, motivation, incentivization or rewarding, coercion or penalizing, training, and restricting. Therefore, it can be summarized that most of the interventions that impact behavioral change for energy efficiency are associated with the human information processing abilities that can be optimally communicated through socio-psychological methods described in the intervention functions of the behavior change wheel ${ }^{[38]}$.

The most crucial aspect of influencing human behavior for energy conservation is knowing the ways they process information. As discussed by Hansen, Kahneman, and Kahneman ${ }^{[39-41]}$, the human mind has reflective and automatic thinking patterns; among them, automatic and particularly nudging has a significant impact on human behavior and, therefore, conservation ${ }^{[23]}$. Nudging is a very dynamic approach that provides people with choice and freedom and is flexible in deploying any other intervention method. Although success has barely been achieved using only one method, the integrated approach has proven efficient. The intention of nudging is not limited to influence behavior only but to increase the user choice and opportunity as a whole. Therefore, this study emphasizes nudging as a pillar that can combine and leverage all the energy conservation methods described in Figure 1 to escalate building energy savings at a larger scale. We further investigate the human behavior influence through nudging mechanism and expand on discovering the type of nudges applied in the building sector.

\section{CONCEPTUAL MODEL AND ITS VALIDATION}

The human consciousness is more rational and relies on memories and knowledge of prior learning. In his book "Thinking, Fast and Slow," Kahneman ${ }^{[4]}$ explains human thinking patterns, such as slow cognition, which is intentional cognition, conscious and reason-based cognition, and fast cognition, that is unconscious or automatic, intuitive, and associated with emotions and feelings. Moreover, Kahneman ${ }^{[0]}$ presents two human information processing systems: system 1, which is based on intuitions or fast processing, and system 2 , which can make rational decisions. The author concludes that system 1 processes most of the information due to less exploitation of active cognition, including mental energy, time, and capacity. System 1 can trigger human choices with no use of any cognitive intervention and is an automatic route of behavioral influence. This route consists of emotional shortcuts, mind priming, and nudging ${ }^{[23]}$. Nudge gives people a choice from their available sources. The choice can relate to the actions they take in everyday life, from eating healthy to managing work stresses and conserving energy resources, as shown in Figure 2. The given scenarios in Figure 2 demonstrate the genuine intention behind nudging, given that 


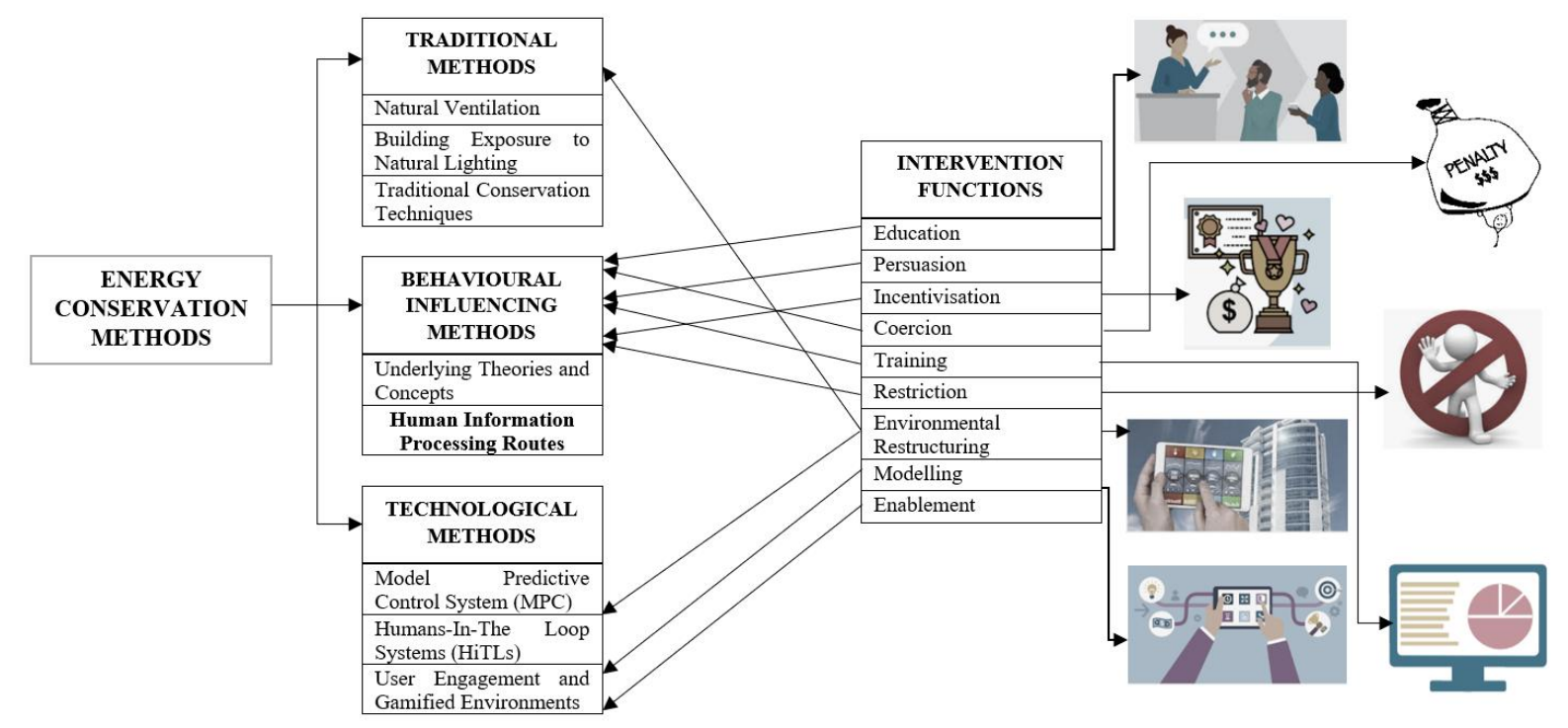

Figure 1. Energy conservation methods.

people have a choice in making health, energy, or eating decisions. We build our research basis and conceptual model on given Behavioral Influencing Tactics adopted by Koop et al..$^{[23]}$, as shown in Figure 2. It can be deduced from Figure 2 that the nudges are less effective when used individually and may not achieve targeted behavioral changes, except that when used by combining individual interventions such as moral appeal, social comparisons, incentives, and user interaction, technologies can amplify nudge effectiveness.

In the context of this research, the nudges are identified as given choices or energy conservation behaviors that occupants undertake without any coercion to promote energy efficiency in buildings. Wong-Parodi et al..$^{[2]}$ describes behavioral interventions as nudges and cite that they are simple to understand, are not constraining, and enable individuals to act in a manner that is aligned with their interests and preferences by leading them to act in favor of specific options. However, it is also instructive to emphasize the argument by Ornaghi et al. ${ }^{[43]}$, who posit that significant behavior change emerges when the targeted behavior is selected carefully, proposed interventions are tuned well, and inexpensive to implement. Likewise, the need for clear feedback to ensure that individuals' actions relate to their outcomes are also highlighted. Additionally, Carrico and Riemer ${ }^{[44]}$ postulate that eliminating feedback from a particular behavior fails to provide the required information, making it difficult for individuals to evaluate whether their actions exert the desired impact. Therefore, to successfully encourage behavior change, there is a need to couple feedback with desired appropriate actions.

Moreover, Table 1 outlines various interventions and their associated outcomes to evaluate the nudge implications of energy use, such as reduced energy consumption and modified occupancy behavior. As evident from the articles in Table 1, technology-based innovations dominated the interventions used in modifying occupancy behavior in commercial buildings. The interventions ranged from phone-based recommendation systems ${ }^{[4]}$ and IoT user engagement systems ${ }^{[46]}$ to proximity sensing beacon technology ${ }^{[47]}$ and eco-feedback system for delivering information ${ }^{[48,49]}$. The findings suggest that technology has become mainstream in monitoring user activity in buildings due to its effectiveness in tracking behavior changes in a fine-grained manner. Moreover, an additional analysis shows that non-technological interventions are also used to modify occupant behavior in the studied commercial buildings. For instance, public displays 
Table 1. Choice architecture for behavioral change

\begin{tabular}{|c|c|c|c|c|c|c|c|c|}
\hline \multirow[b]{2}{*}{ Sources } & \multirow[b]{2}{*}{ Choice Architecture (Methods) } & \multicolumn{5}{|c|}{ Choice Architecture (Intervention Type) } & \multirow[b]{2}{*}{ Outcomes } & \multirow[b]{2}{*}{$\begin{array}{l}\text { Building Type } \\
\text { - Space }\end{array}$} \\
\hline & & $\begin{array}{l}\text { Social } \\
\text { Comparison }\end{array}$ & $\begin{array}{l}\text { Moral } \\
\text { Appeal }\end{array}$ & $\begin{array}{l}\text { Monetary or } \\
\text { Non- } \\
\text { Monetary } \\
\text { Incentive }\end{array}$ & $\begin{array}{l}\text { Information/Feedback } \\
\text { Provided }\end{array}$ & $\begin{array}{l}\text { Technological } \\
\text { Intervention }\end{array}$ & & \\
\hline$[45]$ & $\begin{array}{l}\text { Energy-based recommendation system for lighting } \\
\text { options (mobile app) }\end{array}$ & $x$ & $x$ & $x$ & $\sqrt{ }$ & $\sqrt{ }$ & $\begin{array}{l}\text { Consumers preferred dimmer lighting } \\
\text { when recommendations were } \\
\text { appropriate }\end{array}$ & $\begin{array}{l}\text { Not indicated - } \\
\text { assumption } \\
\text { held is a single } \\
\text { office }\end{array}$ \\
\hline [46] & $\begin{array}{l}\text { Interactive public displays, personalized dashboards, } \\
\text { and alters and notifications }\end{array}$ & $\sqrt{ }$ & $\sqrt{ }$ & $x$ & $\sqrt{ }$ & $\sqrt{ }$ & $\begin{array}{l}\text { Positive behavior change arising from } \\
\text { increased user engagement with loT- } \\
\text { enhanced apps }\end{array}$ & $\begin{array}{l}\text { Smart building - } \\
\text { single and } \\
\text { shared spaces }\end{array}$ \\
\hline [52] & $\begin{array}{l}\text { Green footprints on the floor leading to staircases, } \\
\text { posters with salient injunctive norms, stair-simulating- } \\
\text { messages }\end{array}$ & $\times$ & $\sqrt{ }$ & $x$ & $\sqrt{ }$ & $x$ & $\begin{array}{l}\text { Modified behavior to adopt the use of } \\
\text { stairs } \\
\text { No energy conserved, as elevator use } \\
\text { was reported }\end{array}$ & $\begin{array}{l}\text { University } \\
\text { building - } \\
\text { shared space }\end{array}$ \\
\hline [51] & $\begin{array}{l}\text { Moral appeal, social norms, and stickers (public } \\
\text { displays) }\end{array}$ & $\sqrt{ }$ & $\sqrt{ }$ & $x$ & $\sqrt{ }$ & $x$ & $\begin{array}{l}\text { Reduction in energy consumption when } \\
\text { stickers and social norms were used } \\
\text { together }\end{array}$ & $\begin{array}{l}47 \text { French } \\
\text { company sites - } \\
\text { shared spaces }\end{array}$ \\
\hline [54] & $\begin{array}{l}\text { Relay of real-time energy consumption information } \\
\text { (Eco-feedback systems - website and apps) }\end{array}$ & $x$ & $x$ & $x$ & $\sqrt{ }$ & $\sqrt{ }$ & Improved energy conservation & $\begin{array}{l}\text { Commercial } \\
\text { buildings - } \\
\text { shared space }\end{array}$ \\
\hline [55] & Occupant comfort feedback tool (website) & $x$ & $x$ & $x$ & $\sqrt{ }$ & $x$ & Improved energy conservation & $\begin{array}{l}\text { Shared office } \\
\text { buildings }\end{array}$ \\
\hline [48] & $\begin{array}{l}\text { Eco-feedback system for delivering information } \\
\text { (mobile app) }\end{array}$ & $x$ & $x$ & $x$ & $\sqrt{ }$ & $\sqrt{ }$ & $\begin{array}{l}\text { Change in energy conservation behavior } \\
\text { in response to delivered information }\end{array}$ & $\begin{array}{l}\text { Student } \\
\text { dormitories - } \\
\text { shared space }\end{array}$ \\
\hline [49] & Eco-feedback system (Website - Visual Charts) & $x$ & $\sqrt{ }$ & $x$ & $\sqrt{ }$ & $\sqrt{ }$ & $\begin{array}{l}\text { Change in energy conservation behavior } \\
\text { in response to delivered information }\end{array}$ & Shared space \\
\hline [53] & Satisfaction polling station (public displays) & $x$ & $x$ & $x$ & $\sqrt{ }$ & $x$ & Use of Improved energy conservation & $\begin{array}{l}\text { Enclosed office } \\
\text { buildings }\end{array}$ \\
\hline [56] & $\begin{array}{l}\text { Use of communication systems to relay energy } \\
\text { conservation information (word of mouth) }\end{array}$ & $x$ & $\sqrt{ }$ & $x$ & $\sqrt{ }$ & $\sqrt{ }$ & $\begin{array}{l}\text { Behavior was influenced when female } \\
\text { personas and avatars were used }\end{array}$ & Shared space \\
\hline [57] & $\begin{array}{l}\text { Recommender system that learns user-preferences } \\
\text { from historical data and shares recommendations } \\
\text { (website) }\end{array}$ & $x$ & $x$ & $x$ & $\sqrt{ }$ & $\sqrt{ }$ & Potential energy savings of up-to $72 \%$ & $\begin{array}{l}\text { Shared office } \\
\text { space }\end{array}$ \\
\hline \multirow[t]{2}{*}[58]{} & $\begin{array}{l}\text { Daylighting choice } \\
\text { (immersive virtual environment) }\end{array}$ & $x$ & $x$ & $x$ & $x$ & $\sqrt{ }$ & $\begin{array}{l}\text { Using default settings for lighting it is } \\
\text { possible to improve energy efficiency in } \\
\text { buildings }\end{array}$ & $\begin{array}{l}\text { Single } \\
\text { occupancy } \\
\text { office space }\end{array}$ \\
\hline & $\begin{array}{l}\text { Social feedback prompt, public commitment prompt, } \\
\text { reminder prompt, and explanation prompt }\end{array}$ & $\sqrt{ }$ & $\sqrt{ }$ & $x$ & $x$ & $x$ & $\begin{array}{l}\text { Turning off monitors during non-working } \\
\text { hours reduced energy use in buildings }\end{array}$ & $\begin{array}{l}\text { University } \\
\text { office buildings }\end{array}$ \\
\hline
\end{tabular}


Delivering personalized tailored feedback to impact energy usage (loT-based smartphone energy assistant) (iSEA)

(1) An information dashboard to increase the awareness of the users about their energy

consumption and footprint, (2) a gaming dashboard to

engage users in real-time energy efficiency

competitions, (3) a leaderboard to promote pee

competition and comparison, and (4) a message

dashboard to send tailor-made messages about energy

efficiency opportunities behaviors

building

Office building

The game strategies leveraged

economic, environmental, and social

motivation to influence office occupants'

energy conservation without

compromising their comfort and

autonomy, and $20 \%$ of electricity

savings were observed.

using posters and advertisements ${ }^{[50]}$, use of stickers and moral appeal by word of mouth ${ }^{[51]}$, posters ${ }^{[52]}$, and satisfaction polling stations ${ }^{[53]}$. Such findings suggest increasing information salience through easy-to-understand, and simplified nudges effectively encourage occupant behavior change, similar to technology tools.

The investigation from the literature survey shows that nudges with a minimum variety of choices hardly influence users to conserve energy over long periods. Choice architects need to intuitively design nudges that can provide users with several choices without compromising their comfort. It is evident from Table 1 that user feedback and energy information are crucial in nudging mechanism followed by technological interventions and interactive tools. Therefore, this research emphasizes the effectiveness and ease of nudging mechanism when deployed for energy conservation in buildings.

\section{LITERATURE REVIEW}

\section{Building energy conservation}

Energy conservation has economic benefits and is vital in attaining environmental sustainability and has always been considered before and during building construction phases. The building orientation, location, and proper heating and natural light ventilation have remained traditional energy saving methods in the past ${ }^{[9]}$. The technical solutions and user interventions have their benefits and limitations. Modern control and optimization systems have been designed to minimize energy waste in medium and large-scale commercial buildings. Moreover, the human interaction with the control or building management systems has further created opportunities to save more energy. Despite all such innovations and technical breakthroughs, human influence is still dominant and is inevitable for conserving energy on a large scale.

This paper aims to systematically explore the existing literature on influencing strategies and techniques implemented in buildings for energy conservation. The Theory of Planned Behavior (TPB) ${ }^{[24]}$ was considered the guiding theoretical framework to explore behavioral influences. According to TPB, intentions to undertake a particular behavior can be predicted with high accuracy based on three influential factors: attitudes regarding the behavior, perceived behavioral control, and subjective norms. Justification for adopting TPB in the current research further stems from its adoption in similar studies investigating the effect 


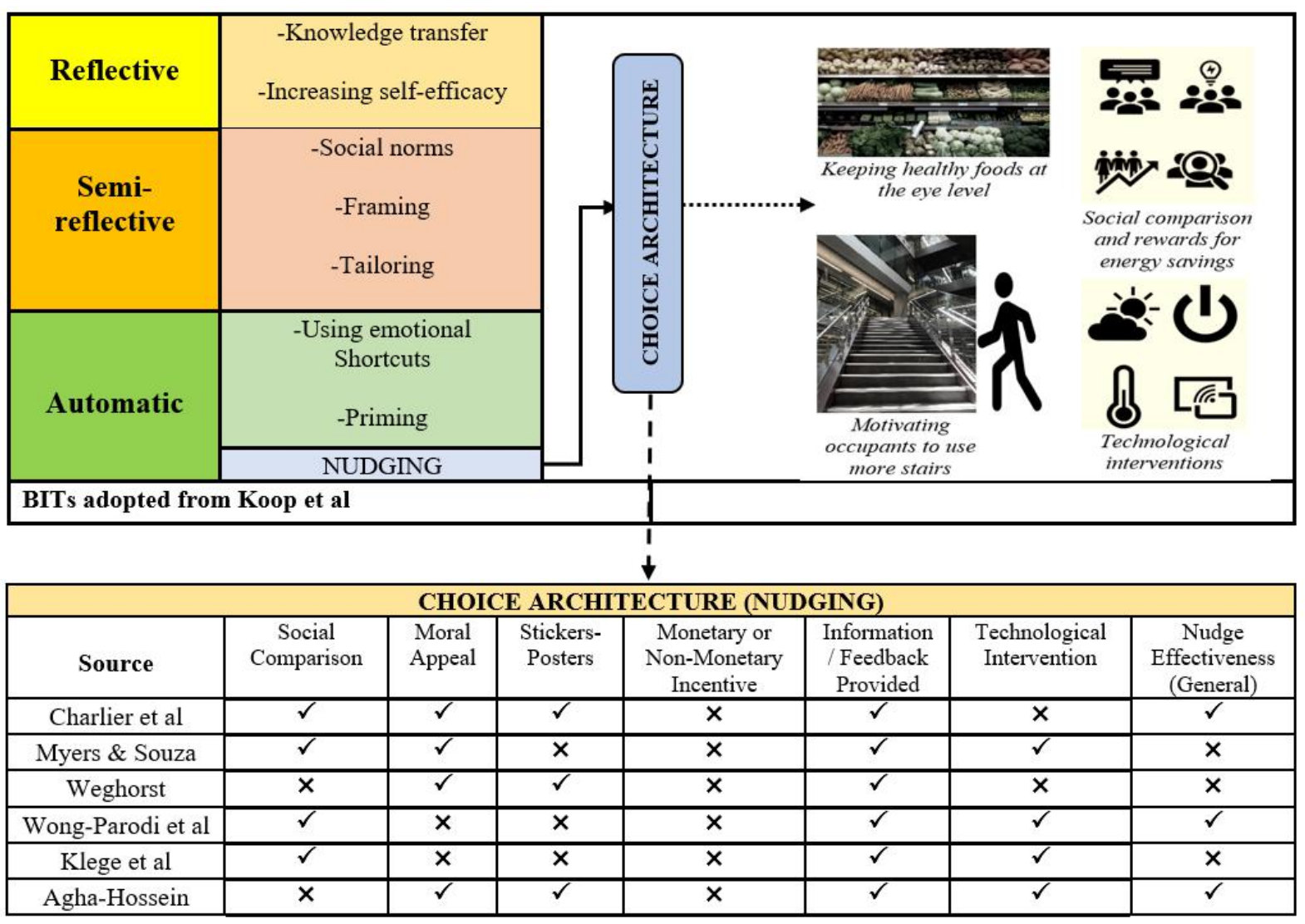

Figure 2. Conceptual model.

of occupant behavior on energy efficiency in buildings ${ }^{[2,63]}$. Occupant behavior, though, has much influence on building energy use but is highly overlooked within the chain of processes involved in building construction, such as design, operation, and maintenance ${ }^{[6,65]}$.

Human behavior is non-trivial in the building energy efficiency context. It is essential to understand how humans process information for exploring opportunities in influencing human behavior for energy conservation. A review conducted to discover behavioral influencing strategies for water household conservation established a framework on the underlying concept of human information processing routes $^{[23]}$. Authors have highlighted three information processing categories, such as reflective, semireflective, and automatic routes, which are further divided into sub-categories making a total number of eight Behavioral Influencing Tactics. Although this research emphasizes the importance of information processing channels associated with human cognition and presents empirical studies on water conservation techniques, a similar framework can help establish influencing energy conservation tactics in buildings.

\section{Nudging for pro-environmental behavior}

Nudging is a tool that provides people with a choice for any particular behavior and has wide applications in environmental sustainability, and is more effective than the traditional policy tools ${ }^{[1,66]}$. Climate change is a serious matter, and humans have a very minimum choice to ignore this inevitable problem for the sake of environmental sustainability and their wellbeing ${ }^{[50]}$. Although public policies are crafted to address global climate issues, the energy nudging concept is vital in this context. It can help individuals build strategies towards environmentally beneficial decisions without impeding their choices ${ }^{[5,51]}$. "Nudges" are being 
widely promoted to encourage energy conservation and altering energy use choices with the help of a nudge framework. They have a significant impact on promoting environmentally friendly behavior ${ }^{[67,68]}$.

Human behavior drastically affects the ecology and biodiversity of the earth ${ }^{[60]}$ and consequently shifts the global climate. Strategies in coping climate change problem and ensuring sustainability relies on human behavior change ${ }^{[10]}$. Nudging is a tool that provides people with a choice for any particular behavior ${ }^{[11]}$. Integrative psychology and economics under the umbrella of behavioral science bring fascinating insights into human decision-making and emphasize the strategies for improving personal health and financial choices but lack investigation for pro-environmental behaviors ${ }^{[69]}$. Although studies by Lehner et al. ${ }^{[10]}$, Mont et al. ${ }^{[11]}$, Cooper ${ }^{[50]}$, Charlier et al. ${ }^{[51]}$, and Hilton et al. ${ }^{[70]}$ demonstrate a nudge mechanism for proenvironmental behavior, digital nudging in the form of digital interfaces has been emphasized as a promising solution to guide peoples' pro-environmental behavior ${ }^{[6]]}$. The overall idea of nudging is to choose to default green rules instead of the options that may be more economical but environmentally dangerous ${ }^{[66]}$.

Furthermore, nudge effectiveness, and its ethical aspects are discussed in Hilton et al. ${ }^{[70]}$. The authors further emphasize a "Good Environmental Nudge" and provide some recommendations on useful and ethical nudges. Research has demonstrated nudges for pro-environmental behaviors ${ }^{[5]}$, and some developed countries such as Europe and the USA have developed platforms that deploy nudging mechanism ${ }^{[11]}$. One study reveals a nudging mechanism to elicit pro-environmental behavior for people who were given the choice of either using elevators or stairs ${ }^{[52]}$. Adopting nudges for sustainable behavior is always challenged from an ethics perspective, where nudges are portrayed as autonomy-reducing or paternalistic style policies ${ }^{[68]}$. Moreover, a favorable implication of energy conservation nudges in households has been investigated from the political view ${ }^{[67]}$.

\section{Nudging tools for energy conservation}

Humans have various psychological biases and defective heuristics that affect their ability to make rational decisions. Policymakers can leverage these biases to increase their range of tools in reducing energy consumption in buildings ${ }^{[7]}$. Various nudge concepts and tools have been proposed and applied in increasing environmentally essential behaviors. These entail default options, change of the social norms, social comparisons, and alterations to the physical environment ${ }^{[10]}$.

\section{Change in default options}

According to the work of Sunstein and Reisch ${ }^{[6 \sigma]}$, the change in the default option can be done when the occupants have complex discretions and are unable to choose a single other option. In this case, the occupants are influenced to save energy because they prefer to make passive choices ${ }^{[10]}$. The default option helps improve energy efficiency by guaranteeing that residents opt-out of energy efficiency options compared to opting in. According to Frederiks et al. ${ }^{[72]}$, the change in default option performs best by targeting energy use behaviors, easily modified through default settings. They also discovered that such options could influence occupants' thought patterns to consider clean energy or energy efficiency as optimal options due to their recommendation by many people. Likewise, Heydarian et al.$^{[58]}$ argued that it was possible to influence occupant behavior towards more energy-efficient choices in their daily interactions with shading and lighting systems in single occupancy office buildings by using default lighting settings.

\section{Social norms and comparisons}

An additional tool, highlighted by Lehner et al. ${ }^{[10]}$, is the implication of social norms and the use of social comparisons. Carrying out comparisons of an individual's consumption to another and those in their social 
network help reduce their energy consumption. For instance, in the study by Liu et al. ${ }^{[73]}$, findings showed that social norms impacted student support for energy conservation efforts in a university campus whereby, $5 \%$ more students signed a petition to adjust thermostats by $2^{\circ} \mathrm{F}$ when they were informed that $90 \%$ of their fellow students agreed to sign the petition. The comparison nudges associated with energy consumption tend to influence the subsequent consumption of energy.

\section{Increasing information salience and simplification}

Studies have discovered that occupants can also be influenced by increasing the information salience and simplification as another nudging tool ${ }^{[10,74]}$. Through the energy star label, buildings that meet the energy standards are identified. Several studies have discovered that changing the physical environment can influence occupant behavior regarding energy use $\mathrm{e}^{[75]}$. The easier it is to understand information, the easier it is to convince an individual to take energy saving measures.

\section{Changing the defaults opt-in vs. opt-out}

The organ donation strategies under 'opt-in' versus 'opt-out' scenarios were discussed in Goldstein et al. ${ }^{[76]}$ demonstrate the cruciality of default options in healthcare. The authors further mentioned that the opt-out was the preferable way people chose to make their names removed from the default donor's list in the countries with maximum organ donations. Conversely, people who had to deliberately register for organ donation (i.e., opt-in), were from countries with a minimum level of organ donations and were considered non-donors by default. It is a known fact that people choose the prevailing standards instead of putting some effort into selecting the different ones, such as completing paperwork, which demonstrates apathetic behavior in psychology. Although default options represent norms, and people consider them global, shifting from them can create uncertainty in making decisions, and individuals choose not to resist them at any cost. Defaults are universal and are considered evolutionary by experts that have been seen in the form of reducing energy use, for instance, $10 \%$ by the end of the year 2010 through a public campaign. Another example is implementing default retirement plans by the authorities in the USA, where employees are encouraged to sign up for employers' retirement plans.

\section{Hyperbolic discounting}

It has been observed in the study by Thaler et al. ${ }^{[77]}$ that people prefer instant gratification instead of the long term benefits of their actions; for instance, they may choose less money immediately instead of having more sometimes later in the future. Firstly, people tend to go for specific options and avoid uncertainty ${ }^{[78]}$. Secondly, individuals see the future as hard and non-tangible, so they undervalue its upcoming incentives. Finally, research suggests that the short-term goals to motivate people to save money or eat healthier foods are useful than asking them to set long-term goals.

\section{Loss and risk aversion}

Loss aversion emphasizes those people who avoid taking risks and who are not ready for potential losses unless the loss is outweighed by the lucrative rewards. Kahn et al. ${ }^{[79]}$ highlight a scenario where people were keen to pay an extra amount in the betting game to minimize the ambiguities. This uncovers the known paradox of the human mind that individuals do not mind not having, but they do mind loosing.

\section{Framing}

People often make decisions based on the given choices and options, and their decision-making becomes much easier when a few options are presented to them instead of many that can be disadvantageous. The studies in behavioral economics reveal that inappropriate choices can crucially impact the decision-making process and make people aware of their actions and behaviors. One study by Ariely et al. ${ }^{[80]}$ highlights that a 
drastic change can happen in making the decision when an individual has to choose from two versus three options.

\section{Reciprocity}

The study by Burger ${ }^{[8]}$ demonstrates that the reciprocity or exchange of something with others is within the fundamental human nature. Some investigations highlight that the organ donation within healthcare has proven to escalate by the campaigning method with the tagline message, "If you need an organ, would you take one?"

\section{Social norms and feedback}

Humans often behave according to what they perceive about themselves from the society or generalized standards of their communities or groups. Experts in behavioral economics have often leveraged social norms in the form of peer pressure to persuade behaviors. It has been found in Nolan et al. ${ }^{[82]}$ that sending users with the feedback of energy use comparison among neighboring houses has a larger impact than the common cost-saving messages. Another research exposes that people are leaned towards artificial norms if they belong to a target group. For instance, the study by Glodstein et al ${ }^{[76]}$ presented that the artificial norms improved towel recycling in hotels. Likewise, Behavioral Influencing Tactics' investigation revealed that individuals conform to paying taxes when they are informed that most neighboring people have already paid the tax. It can be deduced that keeping context-specific norms as precise as possible can lead to maximum behavioral influence.

\section{Management}

Managers can test the effectiveness of interventions and protocols by running the randomized controlled trials at a small scale before implementing them at a larger scale.

\section{Limitations and criticisms}

lthough nudging has been seen as a useful tool to promote pro-environmental or other behaviors, its effectiveness has some limitations. Firstly, the nudging mechanism does not guarantee massive efficiency in influencing behavior. It can produce small or moderate effects, as mentioned by the House of Lord's inquiry on the theory ${ }^{[83]}$. Secondly, core principles discussed in this article are not stable often; for instance, interventions can demonstrate different results on different occasions on subsequent applications. The challenge arises when nudges become prominent, and the users become aware of nudging outcomes and their own decision biases, which could result in lower efficiency. Thirdly, social psychology studies are considered obsolete and conflicting Stroebe et al. ${ }^{[84]}$ The key to ensuring up to date knowledge and information exchange is associated with collaboration and working with diverse academic teams. Fourthly, behavioral science is seemed as a form of soft manipulation of the general public and raises the question of ethicality.

According to Frederiks et al. ${ }^{[72]}$, availing auditory reminders for people who often forget how to act in energy-efficient ways influences their actions towards taking energy-saving approaches. Rafsanjani et al. ${ }^{[00]}$ also reported a similar finding, who argued that the provision of personalized energy-use informationenabled participants to adopt energy aware behaviors in commercial buildings. An IoT-based smartphone energy assistant (iSEA) was developed in their research, enabling occupants to track energy usage through tailor-made personalized feedback. Subsequently, up to $34 \%$ of energy savings were identified by tracking occupants' energy-use efficiency index at the end of the experimental period. Agha-Hossein et al. ${ }^{[85]}$ designed an experiment to test if the interactive posters and prompts, when designed under the Elaboration Likelihood Model, could nudge consumers to change their energy use behavior. The posters were meant to 
raise occupant awareness of adopting energy-saving tactics, such as staircases, offering them metaphorical feedback that was cumulative. The study concludes that the variety of feedback, messages, and rewards when communicated through persuasive technologies may help conserve energy in buildings.

\section{Energy conservation with nudging as an integrated tool}

The implication of nudges is to influence behavior, decision-making, and collaboration processes, and it is imperative to reinforce behavior positively and, additionally, interpolate hints and suggestions. For instance, in the study by Klege et al ${ }^{[86]}$ it was reported that the combination of different behavioral nudges, like interfloor competitions, sharing of regular information, and using floor advocates, led to a $14 \%$ reduction in the use of energy in a 24-story office building in South Africa. A case study by Wong-Parodi et al. ${ }^{[42]}$ on the effect of behavioral change on energy consumption in a university building revealed that the use of feedback strategies regarding social norms led to $10 \%$ less energy consumption during the intervention in comparison to the baseline period. Likewise, in separate research by Yogi ${ }^{[87]}$, a case study of occupants' behavior on a commercial building at Colorado State University was conducted, where guidelines for minimizing the impact of wasteful workstyle on a commercial buildings' energy performance were developed.

Feedback plays a critical role in influencing behavior among building occupants and, as a result, improves energy savings. For instance, Ashouri et al. ${ }^{[88]}$ observed that up to $20 \%$ in savings could be attained by modifying occupant behavior via recommendations and direct feedback on adopting appropriate measures, such as turning off unnecessary lights, HVAC, and ventilation. Khosrowpour et al. ${ }^{[89]}$ posited similar views, citing that feedback programs on energy were created to enhance occupants' energy consumption visibility, thereby improving how they controlled and saved energy. Moreover, Reddy et al. ${ }^{[45]}$ reveal that lightingrelated recommendations can variate energy use in dwellings, and they highlight the importance of user motivation, quality, and content in such recommendations. Likewise, in related research, Pritoni et al. ${ }^{[0]]}$ showed that deployment of "TherMOOstat" software solicited thermal feedback from students in a university campus, improved energy efficiency and comfort. Pritoni et al. ${ }^{[00]}$ showed that deployment of "TherMOOstat" software solicited thermal feedback from students in a university campus, improved energy efficiency and comfort. The findings from the different studies underscore that occupants are more likely to be convinced to change behaviors when receiving feedback on energy consumption. A plausible explanation is that feedback increases awareness of the amount of energy that occupants are required to consume to reduce consumption levels.

Moreover, user-enabled features have become highly desirable in proposing optimal energy-efficient solutions in building design. Several interactive projects in AlSkaif et al.$^{[91]}$ are currently available, providing compelling user-engaging features that influence user energy behavior in buildings. Several interactive projects $^{[91]}$ are currently available, providing compelling user-engaging features that influence user energy behavior in buildings. Similar experiments are conducted in Curry et al. ${ }^{[46]}$ for efficient energy and water management through social networks and interacting technology. Besides, gamification is a recent development tool that emotionally engages users and can change user behavior through positive feedback and gamified rewards ${ }^{[4]}$. It can, therefore, be implied that maximizing energy savings by either incorporating the human-in-the-loop in Bisadi et al..$^{[92]}$ concept or deploying interactive feedback or gamified environments is inevitable for reducing building energy use that can shape future intelligent and sustainable buildings ${ }^{[93]}$.

Three categories of information processing routes, reflective, semi-reflective, and automatic, are presented in the study by Koop et al. ${ }^{[23]}$. Among them, the reflective route is associated with the mind's conscious capability and how knowingly one processes information. However, the semi-reflective route is partially 
conditioned that triggers human cognition on factual information and social norms ${ }^{[23]}$.

This paper particularly emphasizes behavioral nudging and reviews available literature where nudging has been used as a policy tool to conserve building energy. Although various tools and techniques have been used in developing behavioral influencing strategies to achieve pro-environmental goals, nudging can combine other strategies to establish a comprehensive choice architecture. This study aims to showcase various energy conservation strategies and establish that policymakers and designers of the choice architecture should not limit to one strategy instead provide all the possible energy conservation options to users without impeding their comfort and any other incentive. Nudge mechanism is not necessarily useful in all types of buildings or scenarios, and some influencing tactics may outweigh others. As shown in Figure 2, despite using social comparisons, feedback, technology in Klege et al. ${ }^{[86]}$ and Myers et al. ${ }^{[86,94]}$, and moral appeal in Weghorst ${ }^{[52]}$, nudges were ineffective. They did not achieve the desired outcomes in the absence of user incentives. However, the social norm in Wong-Parodi et al.$^{[42]}$ and the combination of poster-prompt in Agha-Hossein et al. ${ }^{[85]}$ resulted in effective nudging strategies in buildings. The combination of multiple nudges such as "Moral Appeal", "Social Comparisons", and "Stickers" mentioned in Charlier et al..$^{[1]}$ demonstrate an ideal example of nudge effectiveness when all integrated.

\section{CONCLUSION AND FUTURE DIRECTIONS}

Traditional energy conservation techniques and sophisticated technology like predictive control systems are in place to minimize building energy use. However, behavioral influencing strategies seem to be more promising in conserving energy in buildings. Findings show that although technical interventions, such as smart meters, could improve a buildings' energy efficiency, significant enhancements could be attained by modifying occupant behavior through nudges. The use of nudges was studied in commercial buildings, such as single-occupancy offices, open-plan offices, and shared office spaces. The use of technological interventions was also observed in modifying occupancy behavior in different commercial buildings, whereby users responded to notifications and recommendations via different kinds of systems. Moreover, it was also observed that non-technological alternatives, such as moral appeal by word of mouth and posters, also effectively influenced occupancy behavior.

Human information processing is the key to understand aspects of influencing energy efficient behavior. The investigations showed that humans process the information unconsciously or through reflection. Nudging mechanism is designed to provide humans with the choices that direct them to make decisions through the automatic or intuitive process. This mechanism does not obscure the freedom of choice. Instead, it facilitates people for making wise decisions conveniently and predictably. Nudging can deploy one or a range of intervention techniques based on the context and requirements. Ideally, a good nudge can combine various influencing strategies through tailor-made interventions to positively reinforce energy efficient behavior. This study has discussed various nudge interventions in commercial, institutional, and office buildings. Besides this, nudging tools can also escalate the energy renovation policies, including uptake of renewable energy technologies by users in residential and commercial buildings. For instance, building users can be motivated to choose solar or thermal solar power systems, install insulated roof and walls, and install energy-efficient appliances, leading to overall energy efficiency improvements.

This research also advocates for adopting agent-based modeling approaches, whereby energy demand complexities, such as spatial constraints and social interactions, would be easily represented and studied. Agent models can be designed by incorporating nudge frameworks and supporting concepts to predict energy savings over specific periods. Agent-based modeling approach is yet to be widely adopted in modeling occupancy behavior towards energy conservation in buildings. Henceforth, it is critical to further 
unfold the potential opportunities of agent-based modeling for modeling occupant behaviors and for evaluating the use of possible interventions. The interventions, if tried and tested in the simulated environments, can then be used to develop policies to persuade inhabitants to change their behavior for building energy conservation.

\section{DECLARATIONS}

\section{Acknowledgments}

Not Applicable.

\section{Authors' contributions}

Conceptualization: Soomro AM, Bharathy G, Biloria N, Prasad M

Methodology and validation: Soomro AM, Bharathy G, Prasad M

Formal analysis: Soomro AM, Bharathy G, Biloria N

Investigation: Soomro AM, Prasad M

Resources: Soomro AM, Bharathy G

Data curation: Soomro AM, Biloria N

Writing-original draft preparation: Soomro AM, Prasad M

Writing-review and editing: Soomro AM, Bharathy G, Biloria N, Prasad M

Visualization: Bharathy G, Biloria N, Prasad M

Supervision: Bharathy G, Biloria N, Prasad M

Project administration: Bharathy G, Prasad M

\section{Availability of data and materials}

Not applicable.

\section{Financial support and sponsorship}

None.

\section{Conflicts of interest}

All authors declared that there are no conflicts of interest.

\section{Ethical approval and consent to participate}

Not applicable.

\section{Consent for publication}

Not applicable.

\section{Copyright}

(c) The Author(s) 2021.

\section{REFERENCES}

1. Ackerman D. Anthropogenic impacts on high-latitude ecosystems: Shrubs will grow. Will nitrogen flow? Retrieved from the University of Minnesota Digital Conservancy, https://hdl.handle.net/11299/206349 [Last accessed on 14 Dec 2020].

2. Conti J, Holtberg P, Diefenderfer J, LaRose A, Turnure JT, Westfall L. International energy outlook 2016 with projections to 2040. United States. Available from: https://doi.org/10.2172/1296780 [Last accessed on 14 Dec 2020].

3. Manu S, Shukla Y, Rawal R, Thomas LE, de Dear R. Field studies of thermal comfort across multiple climate zones for the subcontinent: India Model for Adaptive Comfort (IMAC). Building and Environment 2016;98:55-70. DOI

4. Paone A, Bacher J. The Impact of Building Occupant Behavior on Energy Efficiency and Methods to Influence It: A Review of the State of the Art. Energies 2018;11:953. DOI

5. Du J, Yu C, Pan W. Multiple influencing factors analysis of household energy consumption in high-rise residential buildings: Evidence from Hong Kong. Build Simul 2020;13:753-69. DOI

6. Hu S, Yan D, Guo S, Cui Y, Dong B. A survey on energy consumption and energy usage behavior of households and residential 
building in urban China. Energy and Buildings 2017;148:366-78. DOI

7. Bagchi A. Global construction output to grow 3.6\% per year until 2022 - report 2018. Available from: https://meconstructionnews.com/31872/global-construction-output-to-grow-3-6-per-year-until-2022-report.[Last accessed on 14 Dec 2020].

8. Marcel Moshi A, Guruvasanth S, Samuel PM, Billigraham SS. Effective techniques for energy conservation in buildings - A comprehensive review. Materials Today: Proceedings 2020. DOI

9. Chwieduk DA. Towards modern options of energy conservation in buildings. Renewable Energy 2017;101:1194-202. DOI

10. Lehner M, Mont O, Heiskanen E. Nudging - A promising tool for sustainable consumption behaviour? Journal of Cleaner Production 2016;134:166-77. DOI

11. Mont O, Lehner M, Heiskanen E. Nudging a tool for sustainable behaviour? The Swedish Environmental Protection Agency; 2017. Available from: https://www.researchgate.net/publication/271211332_Nudging_A_tool_for_sustainable_behaviour [Last accessed on 14 Dec 2020].

12. Laaroussi Y, Bahrar M, Elmankibi M, Draoui A, Si-larbi A. Occupant behaviour: a major issue for building energy performance. IOP Conf Ser:Mater Sci Eng 2019;609:072050. DOI

13. Serale G, Fiorentini M, Capozzoli A, Bernardini D, Bemporad A. Model Predictive Control (MPC) for Enhancing Building and HVAC System Energy Efficiency: Problem Formulation, Applications and Opportunities. Energies 2018;11:631. DOI

14. Shareef H, Ahmed MS, Mohamed A, Al Hassan E. Review on Home Energy Management System Considering Demand Responses, Smart Technologies, and Intelligent Controllers. IEEE Access 2018;6:24498-509. DOI

15. Hannan MA, Faisal M, Ker PJ, et al. A Review of Internet of Energy Based Building Energy Management Systems: Issues and Recommendations. IEEE Access 2018;6:38997-9014. DOI

16. Smarra F, Jain A, de Rubeis T, Ambrosini D, D’Innocenzo A, Mangharam R. Data-driven model predictive control using random forests for building energy optimization and climate control. Applied energy 2018;226:1252-72. DOI

17. Yang S, Wan MP, Ng BF, et al. A state-space thermal model incorporating humidity and thermal comfort for model predictive control in buildings. Energy and Buildings 2018;170:25-39. DOI

18. Godina R, Rodrigues EM, Pouresmaeil E, Catalão JP. Optimal residential model predictive control energy management performance with PV microgeneration. Computers \& Operations Research 2018;96:143-56. DOI

19. Martinaitis V, Zavadskas EK, Motuzienė V, Vilutienė T. Importance of occupancy information when simulating energy demand of energy efficient house: A case study. Energy and Buildings 2015;101:64-75. DOI

20. Delzendeh E, Wu S, Lee A, Zhou Y. The impact of occupants' behaviours on building energy analysis: A research review. Renewable and Sustainable Energy Reviews 2017;80:1061-71. DOI

21. Rafsanjani HN, Ahn C. Linking Building Energy-Load Variations with Occupants' Energy-Use Behaviors in Commercial Buildings: Non-Intrusive Occupant Load Monitoring (NIOLM). Procedia Engineering 2016;145:532-9. DOI

22. Niamir L, Filatova T, Voinov A, Bressers H. Transition to low-carbon economy: Assessing cumulative impacts of individual behavioral changes. Energy Policy 2018;118:325-45. DOI

23. Koop SHA, Van Dorssen AJ, Brouwer S. Enhancing domestic water conservation behaviour: A review of empirical studies on influencing tactics. J Environ Manage 2019;247:867-76. DOI PubMed

24. Ajzen I. The theory of planned behavior. Organ Behav Hum Decis Process 1991;50:179-211. DOI

25. Hu H, Fang W, Yu X. Enhancing individual commitment to energy conservation in organizational settings: Identity manipulation for behavioral changes. Resources, Conservation and Recycling 2020;156:104720. DOI

26. Obaidellah UH, Danaee M, Mamun MAA, Hasanuzzaman M, Rahim NA. An application of TPB constructs on energy-saving behavioural intention among university office building occupants: a pilot study in Malaysian tropical climate. J Hous and the Built Environ 2019;34:533-69. DOI

27. Tetlow RM, van Dronkelaar C, Beaman CP, Elmualim AA, Couling K. Identifying behavioural predictors of small power electricity consumption in office buildings. Building and Environment 2015;92:75-85. DOI

28. Allen S, Marquart-pyatt ST. Workplace energy conservation at Michigan State University. IJSHE 2018;19:114-29. DOI

29. Blanke J, Beder C, Klepal M. An Integrated Behavioural Model towards Evaluating and Influencing Energy Behaviour-The Role of Motivation in Behaviour Demand Response. Buildings 2017;7:119. DOI

30. Stern PC, Kalof L, Dietz T, Guagnano GA. Values, Beliefs, and Proenvironmental Action: Attitude Formation Toward Emergent Attitude Objects1. J Appl Social Pyschol 1995;25:1611-36. DOI

31. Sarkis AM. A comparative study of theoretical behaviour change models predicting empirical evidence for residential energy conservation behaviours. Journal of Cleaner Production 2017;141:526-37. DOI

32. Schwartz SH. Are There Universal Aspects in the Structure and Contents of Human Values? Journal of Social Issues 1994;50:19-45. DOI

33. Dunlap RE, Van Liere KD. The "New Environmental Paradigm". The Journal of Environmental Education 2014;9:10-9. DOI

34. Schwartz SH. Normative Influences on Altruism. Advances in Experimental Social Psychology Volume 10. Elsevier; 1977. pp. 22179. DOI

35. Guagnano GA, Stern PC, Dietz T. Influences on Attitude-Behavior Relationships: A Natural Experiment with Curbside Recycling. $J$ Environ Educ 1995;27:699-718. DOI

36. Prochaska JO, Johnson S, Lee P. The transtheoretical model of behavior change. In S. A. Shumaker, J. K. Ockene, \& K. A. Riekert (Eds.), The handbook of health behavior change. Springer Publishing Company; 2009. p. 59-83.

37. Ernecoff NC, Keane CR, Albert SM. Health behavior change in advance care planning: an agent-based model. BMC Public Health 
2016;16:193. DOI PubMed PMC

38. Michie S, van Stralen MM, West R. The behaviour change wheel: a new method for characterising and designing behaviour change interventions. Implement Sci 2011;6:42. DOI PubMed PMC

39. Hansen PG. The BASIC Toolkit: Tools and Ethics for Applied Behavioural Insights. 2019. DOI

40. Kahneman D. Maps of Bounded Rationality: Psychology for Behavioral Economics. American Economic Review 2003;93:1449-75. DOI

41. Kahneman D. Thinking, fast and slow: Macmillan; 2011. Available from: https://us.macmillan.com/books/9780374533557 [Last accessed on 14 Dec 2020].

42. Wong-parodi G, Krishnamurti T, Gluck J, Agarwal Y. Encouraging energy conservation at work: A field study testing social norm feedback and awareness of monitoring. Energy Policy 2019;130:197-205. DOI

43. Ornaghi C, Costanza E, Kittley-davies J, Bourikas L, Aragon V, James PA. The effect of behavioural interventions on energy conservation in naturally ventilated offices. Energy Economics 2018;74:582-91. DOI

44. Carrico AR, Riemer M. Motivating energy conservation in the workplace: An evaluation of the use of group-level feedback and peer education. Journal of Environmental Psychology 2011;31:1-13. DOI

45. Reddy V, Bushree B, Chong M, et al. Influencing Participant Behavior Through a Notification-Based Recommendation System. In: Ham J, Karapanos E, Morita PP, Burns CM, editors. Persuasive Technology. Cham: Springer International Publishing; 2018. pp. 1139. DOI

46. Curry E, Hasan S, Kouroupetroglou C, Fabritius W, ul Hassan U, Derguech W. Internet of Things Enhanced User Experience for Smart Water and Energy Management. IEEE Internet Comput 2018;22:18-28. DOI

47. Konis K, Blessenohl S, Kedia N, Rahane V. TrojanSense, a participatory sensing framework for occupant-aware management of thermal comfort in campus buildings. Building and Environment 2020;169:106588. DOI

48. Ma G, Lin J, Li N. Longitudinal assessment of the behavior-changing effect of app-based eco-feedback in residential buildings. Energy and Buildings 2018;159:486-94. DOI

49. Francisco A, Truong H, Khosrowpour A, Taylor JE, Mohammadi N. Occupant perceptions of building information model-based energy visualizations in eco-feedback systems. Applied Energy 2018;221:220-8. DOI

50. Cooper EJ. To nudge or not to nudge: promoting environmentally beneficial behaviors. (2017). Bard Center for Environmental Policy. 10. Available from: http://digitalcommons.bard.edu/bcep/10 [Last accessed on 14 Dec 2020].

51. Charlier C, Guerassimoff G, Kirakozian A, Selosse S. Nudging electricity consumption within firms. Feedbacks from a field experiment. 2019.

52. Weghorst M. Exploring the possibility of pro-environmental nudging by fine-tuning the stairs versus elevator nudge 2016. Available from: https://dspace.library.uu.nl/handle/1874/341690 [Last accessed on 14 Dec 2020].

53. Lassen N, Goia F, Schiavon S, Pantelic J. Field investigations of a smiley-face polling station for recording occupant satisfaction with indoor climate. Building and Environment 2020;185:107266. DOI

54. Gulbinas R, Taylor JE. Effects of real-time eco-feedback and organizational network dynamics on energy efficient behavior in commercial buildings. Energy and Buildings 2014;84:493-500. DOI

55. West SR, Ward JK, Wall J. Trial results from a model predictive control and optimisation system for commercial building HVAC. Energy and Buildings 2014;72:271-9. DOI

56. Khashe S, Lucas G, Becerik-gerber B, Gratch J. Buildings with persona: Towards effective building-occupant communication. Computers in Human Behavior 2017;75:607-18. DOI

57. Kar P, Shareef A, Kumar A, Harn KT, Kalluri B, Panda SK. ReViCEE: A recommendation based approach for personalized control, visual comfort \& energy efficiency in buildings. Building and Environment 2019;152:135-44. DOI

58. Heydarian A, Pantazis E, Carneiro JP, Gerber D, Becerik-gerber B. Lights, building, action: Impact of default lighting settings on occupant behaviour. Journal of Environmental Psychology 2016;48:212-23. DOI

59. Miller DJ. Behavioral opportunities for energy savings in office buildings: a London field experiment: Centre for Environmental Policy, Faculty of Natural Science, Imperial; 2013.

60. Rafsanjani HN, Ghahramani A, Nabizadeh AH. iSEA: IoT-based smartphone energy assistant for prompting energy-aware behaviors in commercial buildings. Applied Energy 2020;266:114892. DOI

61. Iria J, Fonseca N, Cassola F, et al. A gamification platform to foster energy efficiency in office buildings. Energy and Buildings 2020;222:110101. DOI

62. Heydarian A, Mcilvennie C, Arpan L, et al. What drives our behaviors in buildings? Building and Environment 2020;179:106928. DOI

63. Lopes JRN, Kalid RDA, Rodríguez JLM, Ávila Filho S. A new model for assessing industrial worker behavior regarding energy saving considering the theory of planned behavior, norm activation model and human reliability. Resources, Conservation and Recycling 2019;145:268-78. DOI

64. Reeves B, Cummings JJ, Scarborough JK, Yeykelis L. Increasing Energy Efficiency With Entertainment Media: An Experimental and Field Test of the Influence of a Social Game on Performance of Energy Behaviors. Environment and Behavior 2013;47:102-15. DOI

65. Schakib-ekbatan K, Çakıcı FZ, Schweiker M, Wagner A. Does the occupant behavior match the energy concept of the building? Building and Environment 2015;84:142-50. DOI

66. Sunstein CR, Reisch LA. Automatically green: Behavioral economics and environmental protection. Harv Envtl L Rev 2014;38:127. DOI

67. Costa DL, Kahn ME. ENERGY CONSERVATION “NUDGES” AND ENVIRONMENTALIST IDEOLOGY: EVIDENCE FROM A 
RANDOMIZED RESIDENTIAL ELECTRICITY FIELD EXPERIMENT: Energy Conservation "Nudges" and Environmentalist Ideology. Journal of the European Economic Association 2013;11:680-702. DOI

68. Kasperbauer T. The permissibility of nudging for sustainable energy consumption. Energy Policy 2017;111:52-7. DOI

69. Byerly H, Balmford A, Ferraro PJ, et al. Nudging pro-environmental behavior: evidence and opportunities. Front Ecol Environ 2018;16:159-68. DOI

70. Hilton D, Treich N, Lazzara G, Tendil P. Designing effective nudges that satisfy ethical constraints: the case of environmentally responsible behaviour. Mind Soc 2018;17:27-38. DOI

71. Croson R, Treich N. Behavioral Environmental Economics: Promises and Challenges. Environ Resource Econ 2014;58:335-51. DOI

72. Frederiks ER, Stenner K, Hobman EV. Household energy use: Applying behavioural economics to understand consumer decisionmaking and behaviour. Renewable and Sustainable Energy Reviews 2015;41:1385-94. DOI

73. Liu Y, Veríssimo D, Farhidi F. Using social norm to promote energy conservation in a public building. Energy and Buildings 2016;133:32-6. DOI

74. Sunstein CR. Behavioural economics, consumption and environmental protection. Handbook of Research on Sustainable Consumption. Edward Elgar Publishing; 2015. pp. 313-27. DOI

75. Higham J, Cohen SA, Cavaliere CT, Reis A, Finkler W. Climate change, tourist air travel and radical emissions reduction. Journal of Cleaner Production 2016;111:336-47. DOI

76. Goldstein NJ, Cialdini RB, Griskevicius V. A Room with a Viewpoint: Using Social Norms to Motivate Environmental Conservation in Hotels. J Consum Res 2008;35:472-82. DOI

77. Thaler R, Benartzi S. Save More Tomorrow ${ }^{\mathrm{TM}}$ : Using Behavioral Economics to Increase Employee Saving. Journal of Political Economy 2004;112:S164-87. DOI

78. Bazerman MH, Moore DA. Judgment in managerial decision making: John Wiley \& Sons; 2012. Available from: https://www.wiley.com/en-au/Judgment+in+Managerial+Decision+Making\%2C+8th+Edition-p-9781118065709[Last accessed on 14 Dec 2020].

79. Kahn BE, Sarin RK. Modeling Ambiguity in Decisions Under Uncertainty. J CONSUM RES 1988;15:265. DOI

80. Cropanzano R. Predictably irrational: The hidden forces that shape our decisions. By Dan Ariely, HarperCollins: New York, 2008. ISBN 978-0-06-135323-9. J Behav Decis Making 2010;23:330-1. DOI

81. Burger JM. Increasing compliance by improving the deal: The that's-not-all technique. Journal of Personality and Social Psychology 1986;51:277-83. DOI

82. Nolan JM, Schultz PW, Cialdini RB, Goldstein NJ, Griskevicius V. Normative social influence is underdetected. Pers Soc Psychol Bull 2008;34:913-23. DOI PubMed

83. Science, Committee T. House of Lords-Science and Technology Select Committee 2nd Report of Session 2010-12-Behaviour Change. House of Lords Paper 2011;179. Available from: https:/publications.parliament.uk/pa/ld201012/ldselect/ldsctech/179/179.pdf.

84. Stroebe W, Strack F. The Alleged Crisis and the Illusion of Exact Replication. Perspect Psychol Sci 2014;9:59-71. DOI PubMed

85. Agha-hossein M, Tetlow R, Hadi M, et al. Providing persuasive feedback through interactive posters to motivate energy-saving behaviours. Intelligent Buildings International 2014;7:16-35. DOI

86. Klege R, Visser M, Datta S, Darling M. The Power of Nudging: Using Feedback, Competition and Responsibility Assignment to Save Electricity in a Non-Residential Setting. URL: https://econrsa org/system/files/publications/working_papers/working_paper_763 pdf working paper. 2018. Available from: https://www.ideas42.org/wp-content/uploads/2019/10/working_paper_763.pdf[Last accessed on 14 Dec 2020].

87. Yogi S. Use of BIM-based energy simulations to analyze the impact of occupant behavior on energy performance of commercial buildings: Colorado State University; 2018. Available from: https://hdl.handle.net/10217/185735[Last accessed on 14 Dec 2020].

88. Ashouri M, Fung BC, Haghighat F, Yoshino H. Systematic approach to provide building occupants with feedback to reduce energy consumption. Energy 2020;194:116813. DOI

89. Khosrowpour A, Jain RK, Taylor JE, Peschiera G, Chen J, Gulbinas R. A review of occupant energy feedback research: Opportunities for methodological fusion at the intersection of experimentation, analytics, surveys and simulation. Applied Energy 2018;218:304-16. DOI

90. Pritoni M, Salmon K, Sanguinetti A, Morejohn J, Modera M. Occupant thermal feedback for improved efficiency in university buildings. Energy and Buildings 2017;144:241-50. DOI

91. Alskaif T, Lampropoulos I, van den Broek M, van Sark W. Gamification-based framework for engagement of residential customers in energy applications. Energy Research \& Social Science 2018;44:187-95. DOI

92. Bisadi M, Akrami A, Teimourzadeh S, Aminifar F, Kargahi M, Shahidehpour M. IoT-Enabled Humans in the Loop for Energy Management Systems: Promoting Building Occupants' Participation in Optimizing Energy Consumption. IEEE Electrific Mag 2018;6:64-72. DOI

93. Manic M, Amarasinghe K, Rodriguez-andina JJ, Rieger C. Intelligent Buildings of the Future: Cyberaware, Deep Learning Powered, and Human Interacting. EEE Ind Electron Mag 2016;10:32-49. DOI

94. Myers E, Souza M. Social comparison nudges without monetary incentives: Evidence from home energy reports. Journal of Environmental Economics and Management 2020;101:102315. DOI 